\title{
Simultaneous ionospheric variability on Earth and Mars
}

\author{
Michael Mendillo, Steven Smith, Joei Wroten, and Henry Rishbeth ${ }^{1}$ \\ Center for Space Physics, Boston University, Boston, Massachusetts, USA
}

David Hinson

Department of Electrical Engineering, Stanford University, Stanford, California, USA

Received 28 March 2003; revised 12 August 2003; accepted 21 August 2003; published 9 December 2003.

[1] Ionospheric physics deals with the basic structure and variability of plasma within the upper atmospheres of the Earth and planets. Comparative studies foster both exploration and synthesis within diverse settings. In this paper we examine observations of the ionospheric profiles on Mars obtained on 9-27 March 1999 by the radio science experiment onboard the Mars Global Surveyor satellite, and compare their day-to-day variability with same-day observations on Earth. Using photochemical-equilibrium arguments applicable to the peak electron density layer on Mars and the E-layer on Earth, we find basic agreement in scaling laws between the planets, and in the details of correlations with simultaneous solar flux variations during a period of pronounced solar activity. We ascribe the residual variabilities (larger on Mars than Earth) to both observational uncertainties and to nonsolar mechanisms in need of further study on both planets. INDEX TERMS: 6225 Planetology: Solar System Objects: Mars; 2479 Ionosphere: Solar radiation and cosmic ray effects; 7537 Solar Physics, Astrophysics, and Astronomy: Solar and stellar variability; 5435 Planetology: Solid Surface Planets: Ionospheres (2459); KEYWORDS: ionospheric variability, comparative aeronomy, Mars ionosphere, solar-planetary relations, photochemical ionospheres

Citation: Mendillo, M., S. Smith, J. Wroten, H. Rishbeth, and D. Hinson, Simultaneous ionospheric variability on Earth and Mars, J. Geophys. Res., 108(A12), 1432, doi:10.1029/2003JA009961, 2003.

\section{Introduction}

\subsection{Comparative Ionospheres}

[2] The ionized component of a planet's upper atmosphere depends on a blend of in situ production and loss processes, plus effects of transport of ionization into or out of the local region of interest. As described in basic texts on ionospheric physics [Ratcliffe, 1960; Davies, 1969; Rishbeth and Garriott, 1969; Bauer, 1973; Banks and Kockarts, 1973; Kelley, 1989; Hargreaves, 1992; Schunk and Nagy, 2002], each of these processes enjoys a mature level of understanding. Computer models of the terrestrial ionosphere are plentiful [Schunk, 1996, 2002] and each ionosphere in our solar system has at least one model [Nagy and Cravens, 2002].

[3] The truly common input for all solar system ionospheres on a given day is the Sun's photon flux, a simple function of heliospheric distance. All other effects are planet specific: (1) rotation rate and solar obliquity conditions, (2) the thermal structure, constituent reactions, and dynamics of its neutral atmosphere, (3) the degree to which energetic particles (of solar wind and/or magnetospheric origin) impinge upon its atmosphere, (4) diffusion and electrody-

\footnotetext{
${ }^{1}$ Also at Department of Physics and Astronomy, University of Southampton, Southampton, UK.

Copyright 2003 by the American Geophysical Union. 0148-0227/03/2003JA009961\$09.00
}

namics associated with coupling from above, and (5) tides, waves, and electrodynamics arising from coupling to regions below.

[4] Given the variety of possible ionospheres in our solar system that might result from these variable processes, it is not obvious, a priori, which of the planets would have the greatest electron density. One approach to a solar-systemwide assessment is to focus on the dominance of the in situ mechanisms: production by solar radiation and chemical loss. Fortunately, as we shall see, there are ionospheric layers on each planet for which plasma dynamics is either unimportant or its importance occurs at heights well above the regions of peak solar production and dominant chemical loss. In the next section, we review briefly the photochemical basis of such ionospheric regions and then apply the results to known ionospheres over a span of 30 astronomical units (AU) in the solar system.

\subsection{Photochemical Ionospheres}

[5] Ionospheric physics at each planet involves a local blend of two fundamental regimes: photochemical processes and neutral/plasma dynamics. On Earth, where photochemical processes are reasonably well understood, dynamical effects related to upward and downward coupling are used to explain the departures often observed from the predictions of simple photochemistry. Such attempts for other planets are far less constrained because of the lack of comprehensive measurements of ionospheric parameters. In this section, we review briefly the most general formu- 
lation of a photochemical ionospheric layer in order to explore its ramifications as a base level description of ionospheres throughout the solar system. We conclude the section with a discussion of how simplifying assumptions employed in such a formulation affect scaling laws for ionospheric behavior among the planets.

[6] If all planetary atmospheres had (1) a single molecular gas that is photoionized to form a molecular ion, (2) for which dissociative recombination is the dominant loss process, (3) located in a dense atmosphere, making transport negligible, and (4) with no magnetospheric or solar wind interaction (or considering latitudes and altitudes where they are small), then simple photochemical equilibrium would govern each planet's peak electron density. Under such conditions, the daytime electron (and ion) density $\mathrm{N}$ is never far from the steady state value derived from "Chapman theory" [Chapman, 1931; Rishbeth and Garriott, 1969; Bauer, 1973]. In this situation, the rate of loss $\alpha \mathrm{N}^{2}$ (where $\alpha$ is the recombination coefficient) balances the rate of production P, i.e.,

$$
\mathrm{P}=\alpha \mathrm{N}^{2},
$$

where

$$
\mathrm{P}=\mathrm{n}(\mathrm{M}) \eta \sigma \mathrm{Se}^{-\tau} / \mathrm{D}^{2} .
$$

[7] Here, D represents heliocentric distance in AU, S represents the photon flux of solar ionizing radiation outside the atmosphere at $1 \mathrm{AU}, \tau$ represents the optical depth for the ionizing radiation, $\mathrm{n}(\mathrm{M})$ represents the molecular number density, $\sigma$ represents the cross-section for absorption of the ionizing radiation, and $\eta$ represents the "ionization efficiency" (number of electrons produced per photon absorbed).

[8] For a single ionizable gas $\mathrm{M}$, the optical depth $\tau$ at any point is given by an integral along the path between that point and the Sun. For an exponential atmosphere with scale height $\mathrm{H}$, at solar zenith angle $\mathrm{\chi}$, the integration results in the equation

$$
\tau=\mathrm{n}(\mathrm{M}) \sigma \mathrm{H} \sec \chi .
$$

Practical observations are often concerned with the maximum electron density $\mathrm{N}_{\mathrm{m}}$ of an ionospheric layer. The peak of a photochemical ("Chapman") layer lies near the level of unit optical depth $(\tau=1)$. Imposing the condition $\tau=1$ in equations (2) and (3) gives the equation for the peak production rate at the height of the peak, $\mathrm{h}_{\mathrm{m}}$ (where $\mathrm{e}=$ 2.718...):

$$
\mathrm{P}_{\mathrm{m}}=\mathrm{S} \eta \cos \chi / \mathrm{eHD}^{2} .
$$

This expression is independent of both $\mathrm{n}(\mathrm{M})$ and $\sigma$, which through equation (3) determine the height $\mathrm{h}_{\mathrm{m}}$ at which the peak forms but not the peak density. Equating equations (1) and (4) yields the result that the maximum ionospheric electron densities scale inversely with distance from the Sun:

$$
\mathrm{N}_{\mathrm{m}}=[\mathrm{S} \eta \cos \chi / \mathrm{eH} \alpha]^{1 / 2} / \mathrm{D} .
$$

For Earth, the classic example of this process is the formation of $\mathrm{O}_{2}^{+}$from $\mathrm{O}_{2}$. In other planetary cases, the molecular ion produced by photoionization of the dominant neutral species (e.g., $\mathrm{CO}_{2}^{+}$for Mars and Venus, and $\mathrm{H}_{2}^{+}$for jovian planets) can react very rapidly with ambient neutrals to form a different molecular ion (e.g., $\mathrm{O}_{2}^{+}$and $\mathrm{H}_{3}^{+}$). The terrestrial analogy is the rapid transformation of $\mathrm{N}_{2}^{+}$to $\mathrm{NO}^{+}$. For our purposes, this simply means that photoproduction leads to a dominant daytime molecular ion, not necessarily the ion that is originally formed, on time scales faster than any possible plasma dynamics. This assumption, that the photochemical situation is not materially altered by charge-exchange or other reactions (such as attachment of electrons to form negative ions), so that the plasma exists as molecular ions and electrons, is central to our analysis. There are, however, other provisos associated with these equations:

[9] 1. Because $\eta, \sigma$, and $\mathrm{S}$ are all wavelength dependent, integration over the whole ionizing waveband, and summation over all ionizable gases, is needed to evaluate $\mathrm{P}$ properly. For present purposes we may continue to use the simple equations if we consider $\eta$ and $\sigma$ to be appropriately weighted averages, and $\mathrm{S}$ the total ionizing flux.

[10] 2. The appropriate numerical value of the flux $\mathrm{S}$ at 1 AU differs between planets because the wavelength range of the ionizing radiation depends on the ionizable gas.

[11] 3. Similarly, the cross-section $\sigma$ and the ionization efficiency $\eta$ depend on the gas being ionized at each planet.

[12] 4. The scale height $\mathrm{H}$ depends not only on the mass of the ionizable gas but also on the temperature in each planetary atmosphere and the planet's gravity.

[13] 5. If $\mathrm{H}$ varies with height, an extension of Chapman theory [Nicolet, 1951] shows that the exponent of $\cos \chi$ in equations (4) and (5) is modified from 1 to $(1+\mathrm{dH} / \mathrm{dh})$, which for the terrestrial E-layer is about 1.5. Chapman theory can be further extended to take account of grazing incidence (i.e., $\chi$ approaching $90^{\circ}$ ). For present purposes we do not incorporate these refinements.

[14] 6. The dissociative recombination coefficient $\alpha$ depends on the reactants present and on their temperatures and vibrational states.

[15] Keeping to these assumptions, and returning to equation (3), another useful relation emerges, one based on the fact that the product of neutral gas concentration $n$ and neutral scale height $\mathrm{H}$ is proportional to column content. Thus for overhead Sun $(\chi=0)$, an ionospheric peak occurs at the same column content on any planet (and, through the hydrostatic equation, to pressure). These statements, too, are subject to proviso 3 about the cross-section $\sigma$, and to others:

[16] 7. If the loss coefficient $\alpha$ or the scale height $\mathrm{H}$ are height-varying, the level of peak production may not coincide with the level of maximum electron density (In practice, the difference between them is only a fraction of a scale height).

[17] 8. The relation between optical depth and pressure depends on molecular mass and gravity, which vary from planet to planet.

[18] With concerns 1 through 8 all duly noted, there is still utility in saying sunlight is sunlight and molecules in 


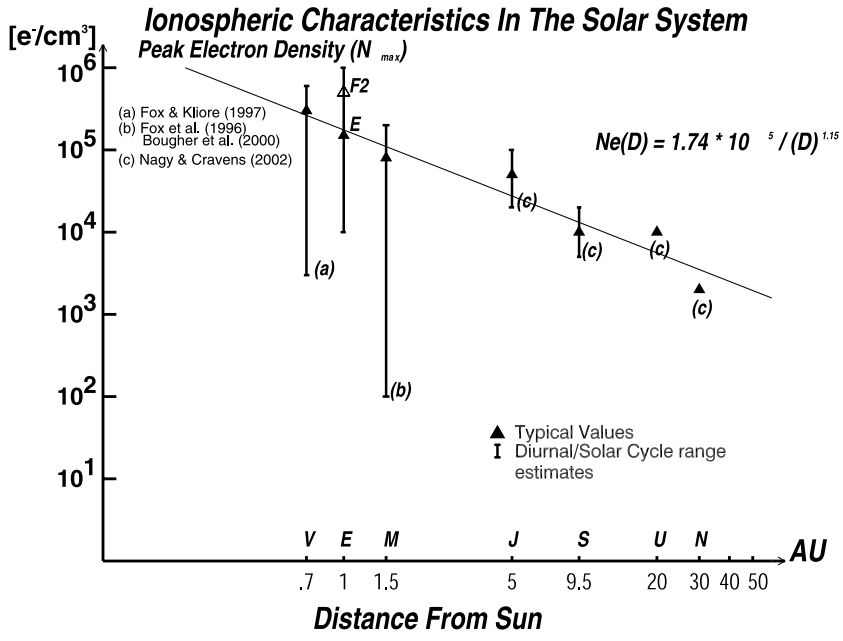

Figure 1. A summary of ionospheric characteristics in the solar system. The solid triangles and vertical lines give typical values and ranges of the maximum electron density for the photochemical ionospheric layers at the seven planets with permanent and substantial atmospheres. For Earth, two values are given, an open triangle for the F2-layer and a solid triangle for daytime E-layer. A best fit curve to the seven solid triangles using the dependence shown in equation (5) is given. See text for discussion.

an atmosphere are similar and thus proceed with equation (5) as an initial framework for comparative ionospheric scaling.

\subsection{Observations of Ionospheres in the Solar System}

[19] The most recent summary of planetary ionosphere appears in the work of Nagy and Cravens [2002]. We refer the reader to that work and references therein for a planetby-planet account of the dominant photochemical processes responsible for the main ionospheric layer at each planet. As also pointed out in the work of Nagy and Cravens [2002], Venus has the most completely observed extra-terrestrial ionosphere, with the four jovian planets having only a few profiles available from satellite "fly-by" encounters, and these yield far from consistent descriptions. In Figure 1 we offer an attempt to summarize the diverse measurements of peak electron densities for the seven planets with substantial atmospheres in our solar system. In virtually all of the nonterrestrial cases, the measurements are not at the subsolar point or at the same levels of solar activity. Thus uncertainty ranges spanning diurnal, seasonal and solar cycle values are also indicated for the three terrestrial planets, and for Jupiter and Saturn (estimates that probably apply to Uranus and Neptune as well).

[20] Clearly, there is not an overall $1 / \mathrm{D}$ pattern as equation (5) would suggest: the peak density does not occur on the innermost planet but on the third one (depicted by the open triangle symbol at the 1 AU position). The reason is again photochemical in origin: the conditions leading up to equation (5) do not hold for the Earth's F2-layer, where the maximum electron density occurs. Atomic oxygen $(\mathrm{O})$ is the main ionizable gas in the F-region and the resulting $\mathrm{O}^{+}$ ions cannot recombine with electrons via dissociative recombination, thus violating both the fundamental photo- chemical assumptions that lead to equation (5). Electrons in the terrestrial F2 layer are lost by a slow two-stage process involving reactions with neutral $\mathrm{N}_{2}$ and $\mathrm{O}_{2}$, and thus the rate of electron loss at the peak is of the form $\beta \mathrm{N}_{\mathrm{m}}$ rather than $\alpha \mathrm{N}_{\mathrm{m}}^{2}$ [Rishbeth and Garriott, 1969]. Finally, plasma transport is highly significant for the F2-layer, a factor not included in equations (1) to (5). For all of these reasons, the F2-layer's peak electron density $\left(\mathrm{N}_{\mathrm{m}} \mathrm{F} 2\right)$ is not the appropriate parameter to represent the Earth in Figure 1, where all other planets have their peak densities in a pure photochemical layer.

[21] The terrestrial ionosphere has photochemically controlled electron density layers below the peak layer, as do several of the planets. The E-layer at $100-120 \mathrm{~km}$ is produced by EUV of about 900-1000 $\AA$ and X-rays, and the F1-layer at $170-200 \mathrm{~km}$ is produced by shorter EUV (roughly 200-900 А). These two layers are the ones most consistent with the assumptions leading to equation (5). For reasons discussed more fully below (dealing with F1-layer departures from pure photochemical equilibrium), we select the terrestrial E-layer for appropriate comparisons with Mars and thus add a typical value of its peak density $\left(\mathrm{N}_{\mathrm{m}} \mathrm{E}\right)$ at the $1 \mathrm{AU}$ position in Figure 1. With this single change, the pattern of $\mathrm{N}_{\mathrm{m}} \sim 1 / \mathrm{D}$ is clearly more apparent for all the solid triangle symbols (denoting photochemical layers) in Figure 1. Indeed, a least squares fit to the seven solid triangle points in Figure 1 gives an empirical scaling result consistent with the dependence shown in equation (5). While this trend spans the solar system, subtrends seem to exist for the terrestrial planets and for the jovian planets when taken separately. These subtrends are related to the parameters taken to be first-order constants in equation (5) when in fact they can vary. Yet, as discussed above, there are only two main molecular ions $\left(\mathrm{O}_{2}^{+}\right.$and $\left.\mathrm{H}_{3}^{+}\right)$found among the seven photochemically dominant peak layers in the solar system, thus accounting for the consistent picture suggested by Figure 1.

\subsection{Approach to Earth-Mars Comparative Ionospheric Studies}

[22] The goal of this paper is to conduct the first detailed comparative study of two solar-controlled ionospheres, terrestrial and martian, to test the scaling laws with distance and day-to-day solar variability embodied in equation (5). Bougher et al. [1999, 2002] have provided comprehensive summaries of the upper atmospheres of the terrestrial planets, and we will draw from those studies for the discussions below. As will be seen, there are two ionospheric layers on Mars and two on Earth that could form the bases of a comparative study of photochemical ionospheres. For Mars, the maximum electron density occurs near $135 \mathrm{~km}$ where the pressure is $\sim 5 \times 10^{-7}$ mbar and the dominant ion is $\mathrm{O}_{2}^{+}$. Photons below $\sim 900 \AA$ (and primarily at $304 \AA$ ) provide the ionization source of $\mathrm{CO}_{2}$, and rapid chemistry converts $\mathrm{CO}_{2}^{+}$to $\mathrm{O}_{2}^{+}$[Nagy and Cravens, 2002]. A secondary ledge of molecular ions and electrons occurs near $110 \mathrm{~km}\left(10^{-5} \mathrm{mbar}\right)$, produced primarily by soft X-rays (18-150 ̊) [see Bougher et al., 2001, and references therein]. Understanding the main ionospheric layer at $135 \mathrm{~km}$ on Mars is clearly the best starting point for comparative studies: it is more readily (and reliably) observed, and the solar wavelengths responsible for its 
production conform more directly to those responsible for the terrestrial $\mathrm{E}$ and $\mathrm{F} 1$ layers.

[23] For Earth, the E-layer plasma $\left(\mathrm{e}-, \mathrm{O}_{2}^{+}, \mathrm{N}_{2}^{+}, \mathrm{NO}^{+}\right)$is well represented by the physics embodied in equation (5). It occurs at $\sim 110 \mathrm{~km}$ where the pressure level is $\sim 8 \times$ $10^{-5}$ mbar. The F1 layer is typically at $\sim 3 \times 10^{-6} \mathrm{mbar}$ and thus from our discussion of optical depth, column content, and pressure in section 1.2, it might appear to be the better layer for comparative studies with the peak layer on Mars. Yet, the F1-layer (which is more of a "ledge" than a "layer") is primarily formed by the ionization of atomic oxygen $(\mathrm{O})$, a process of minor importance on Mars. In addition, only some of the terrestrial $\mathrm{O}^{+}$ions are subsequently converted to molecular ions. Thus the F1-layer is a transition region between the predominance of atomic and molecular ions, and consequently the electron loss processes involve a blend of the $\beta \mathrm{N}_{\mathrm{m}}$ and $\alpha \mathrm{N}_{\mathrm{m}}^{2}$ regimes mentioned above. The associated time constants for loss range from seconds to tens of minutes (e.g., as shown in the work of Banks and Kockarts [1973]), indicating that dynamics start to become important as the F1 layer merges into the F2 layer. Observationally, the F1 peak density is often difficult to identify unambiguously in ionograms, and thus attempts to characterize its day-to-day variability are fraught with uncertainty. An excellent summary of E region observations and modeling using the most recent reaction rates and atmospheric parameters has been given by Titheridge [2000], with the problem of E-F1 layer transition physics and detection explored in the work of Titheridge [2003].

[24] Based on the above discussion, i.e., for reasons both physical and practical, we will adopt the purely photochemical terrestrial E-layer as the appropriate one for observational comparisons with the maximum electron density on Mars. Embodied in this decision is a departure from the terminology normally applied to Mars, i.e., referring to its peak layer as an F1 layer [Bougher et al., 2001; Fox et al., 1995]. That legacy came from the need to give a physical explanation for the different altitudes of the Earth's E and F1 layers. The very reasonable solution was to relate them to the depths of penetration and ionization by solar radiation versus wavelength in the terrestrial atmosphere [Rishbeth and Garriott, 1969; Bauer, 1973]. In this way, the concept of an ionospheric layer became a wavelength dependent phenomenon. Within the larger context of the other planets (as well as comets and stars), we think a wavelength band-of-origin distinction is a less transferable nomenclature than a distinction based on the dominance or not of photochemistry.

\section{Earth's Ionosphere: Variability Patterns}

[25] All of the ionospheric processes mentioned in section 1 were discovered on Earth. The observational database started with routine ionosonde measurements in 1931 [Rishbeth, 2001] and, to a large extent, theory and simulations followed experimental and observational advances. Among the terrestrial planets, Earth is the largest, its gravity is the strongest, and its magnetosphere is unique. Its ionosphere spans an altitude range of $\sim 60-2000 \mathrm{~km}$, a significant fraction of its radius $(\sim 30 \%)$, and the overall solar-terrestrial-interaction domain ("geospace") is measured in decades of Earth radii.
[26] There is a rich history of modeling the global morphologies of the Earth's photochemical ionospheric layers (e.g., Appleton [1959] to Titheridge [2003]). The same can be said for the F2-layer physics that requires solution of the full continuity equation (production-losstransport). As reviewed recently by Forbes et al. [2000], Fuller-Rowell et al. [2000], and Rishbeth and Mendillo [2001], the specification and modeling of the complex F2-layer patterns are well in hand for time scales ranging from seasons to solar cycles. Understanding the variations during episodic periods of geomagnetic activity and the day-to-day variability driven by coupling from below are two main areas of current research in terrestrial aeronomy. As an illustration of day-to-day effects, we show in Figures 2 and 3typical E, F1 and F2 layer peak densities and their variabilities from ionosonde stations in Bermuda and Florida for the month of March 1999. These sites were selected for this illustration because they are in the same longitude sector, and their latitudes are well equatorward of any persistent influence of auroral zone processes; in addition, they are sufficiently poleward to avoid variability effects caused by the electrodynamics that forms the equatorial ionization anomaly (EIA) or "fountain effect" at low latitudes. The top panels show the diurnal curves of $\mathrm{N}_{\mathrm{m}} \mathrm{F} 2$ for the month, and the second panels describe their variability (defined as the standard deviation about the mean). The corresponding data for the $\mathrm{N}_{\mathrm{m}} \mathrm{F} 1$ and $\mathrm{N}_{\mathrm{m}} \mathrm{E}$ layers, and their variabilities, are in the lower four panels. Note that nighttime densities in the E and F1 layers are too low to measure using standard ionosonde techniques.

[27] For the panels in Figures 2 and 3 containing the diurnal curves of $\mathrm{N}_{\mathrm{m}} \mathrm{F} 2, \mathrm{~N}_{\mathrm{m}} \mathrm{F} 1$ and $\mathrm{N}_{\mathrm{m}} \mathrm{E}$, there is an excellent consistency in their absolute values (giving virtually identical monthly mean values), as would be expected for geographically similar stations. Of particular interest for this study are the E and F1 patterns. The first thing to note is that the number of observations of an E-layer exceeds the number of detections of an F1-layer at the same location. This demonstrates the problem of trying to monitor the F1-layer on a daily basis using an ionosonde. Yet, when available, $\mathrm{N}_{\mathrm{m}} \mathrm{F} 1$ values should be more or less in proportion to $\mathrm{N}_{\mathrm{m}} \mathrm{E}$, and this is indeed reflected in their monthly mean values. According to the formulas in the work of Rishbeth and Garriott [1969] which give mean values for $\mathrm{N}_{\mathrm{m}} \mathrm{E}$ and $\mathrm{N}_{\mathrm{m}} \mathrm{F} 1$ as a function of sunspot number, their ratio should be $\sim 2$ for the solar activity prevailing in March 1999, as this is the case in Figures 2 and 3. The situation is rather different, however, for variabilities in each layer.

[28] Consider first the variabilities for the F2 and E layers: the variability of $\sim 20 \%$ (daytime) and $15-40 \%$ (nighttime) for the F2-layer and $\sim 5-7 \%$ (mid-day) for the E-layer are consistent at the two sites separated by $\sim 2100 \mathrm{~km}$; their magnitudes are in agreement with many earlier studies. For the F2-layer, it is well recognized that day-to-day variability of the ionosphere above any site results from three independent sources: (1) solar photon variations, (2) magnetospheric activity, and (3) coupling from the mesosphere-stratosphere-troposphere (collectively called "met" for "meteorological"). In the work of Rishbeth and Mendillo [2001], these were characterized as:

$$
\Sigma^{2}(\text { total })=\Sigma^{2}(\text { solar })+\Sigma^{2}(\text { geomag })+\Sigma^{2}(\text { met }) .
$$




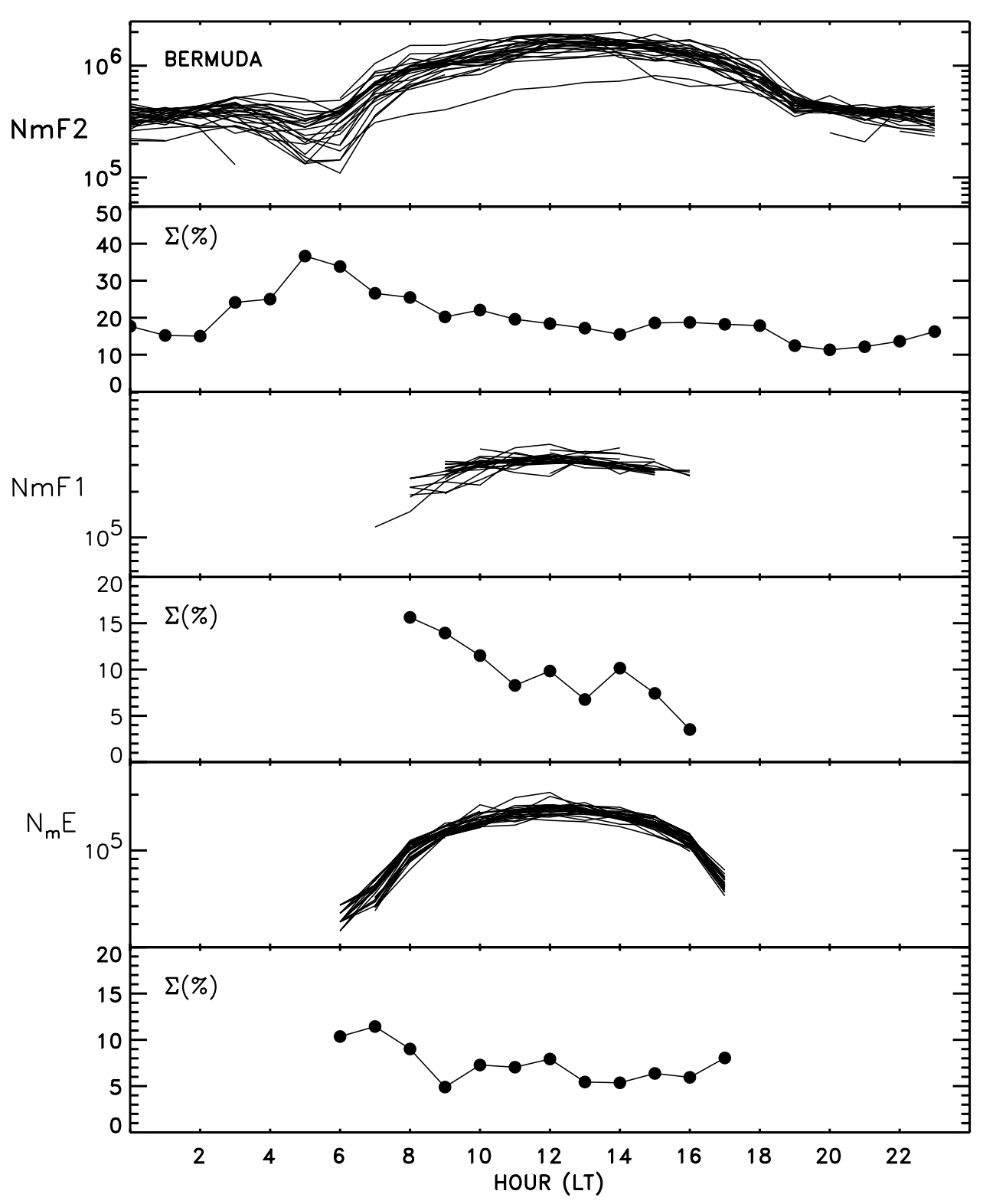

Figure 2. Examples of terrestrial ionospheric variability at a midlatitude site (Bermuda, $32^{\circ} \mathrm{N}, 64^{\circ} \mathrm{W}$ ). Top panels give F2-layer diurnal curves of $\mathrm{N}_{\mathrm{m}} \mathrm{F} 2$ and their variability $(\Sigma)$, defined as the standard deviation (in percent) about the monthly mean. Lower panels give simultaneous diurnal patterns for the F1-and E-layer peak densities and their variabilities.

For the daytime F-region, they were found to be $\sim 3 \%$, $13 \%$, and $15 \%$, respectively, essentially consistent with Forbes et al. [2000]. Clearly, day-to-day changes in solar radiation exert a very minor influence upon the F2-layer in comparison to those driven by dynamical effects imposed from above and below.

[29] For the E-layer, the day-to-day variations are much smaller than those in the F2-layer, and it is reasonable to attribute them predominantly to photochemical effects (with perhaps some contribution from tidal effects at the two sites). Titheridge [2000] found a $\sim 6 \%$ variability for the E-layer, consistent with the earlier studies by Kouris and Muggleton [1973a, 1973b], and certainly with the patterns shown in the bottom panels of Figures 2 and 3.
[30] For the F1-layer, however, the two stations do not show consistent variabilities. The mid-day value at Eglin (Florida) is $\sim 15 \%$, nearly double that at Bermuda. Such a noticeable difference between two nearby stations reinforces our concerns expressed earlier about using terrestrial F1-layer analogies for Mars, and again for both observational and physical reasons. The visibility and shape of the F1 ledge in ionosonde traces depend sensitively on the quantities $\alpha, \beta$, and $\mathrm{P}$ discussed above, which are affected by changes in neutral gas composition, and probably also by geomagnetic activity and atmospheric waves. Relating F1-layer variabilities to solar input alone cannot be done with any confidence. Thus, we conclude that the terrestrial E-layer data from ionosondes is the appropriate source for 


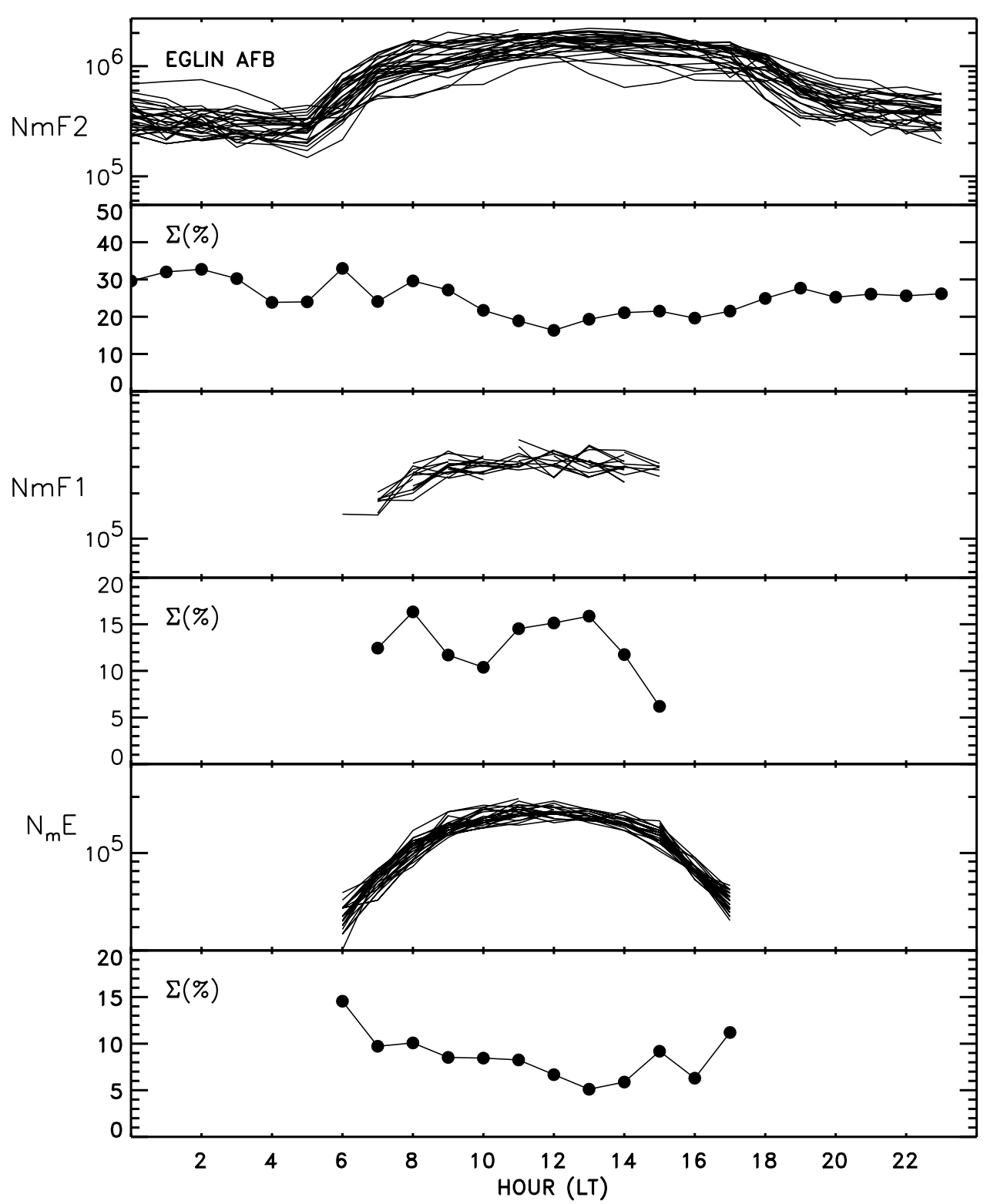

Figure 3. Same as in Figure 2, but for ionosonde data from Eglin, Florida $\left(30^{\circ} \mathrm{N}, 86^{\circ} \mathrm{W}\right)$.

comparative studies with the main photochemical layer at Mars.

\section{Ionosphere of Mars}

[31] The planet Mars offers an interesting contrast to the terrestrial ionosphere. The Sun's photon flux is lower and, with no global magnetic field to shield it from the solar wind, heliospheric particles and fields can also have a direct impact upon Mars' upper atmosphere. While its atmosphere at the surface is far thinner than Earth's, the abundance of molecules near $130 \mathrm{~km}\left(\mathrm{CO}_{2}\right.$ for Mars and $\mathrm{N}_{2}$ for Earth) are rather similar $\left(\sim 10^{11} \mathrm{~cm}^{-3}\right)$. Photochemical equilibrium thus controls the electron density at its peak height $\left(\mathrm{h}_{\mathrm{m}} \sim 135 \mathrm{~km}\right)$ and below. The scale height and mean free path are comparable at $200 \mathrm{~km}$, thus defining an exosphere relatively close to the peak of the ionosphere. Moreover, the solar wind stand-off height ("ionopause") is typically at $350 \mathrm{~km}$, and thus magnetosphere-ionosphere interactions (so important on
Earth) are replaced by solar wind-ionosphere interactions at Mars. The total domain of ionospheric structures on Mars thus spans a height range of only $\sim 10 \%$ of its radius.

[32] Two processes of coupling from below again distinguish Mars from Earth: (1) the planet is small and yet its orographic features are dramatic, and thus tides and wave forcing from below occur to a degree not seen on other terrestrial planets [Forbes and Hagan, 2000; Forbes, 2002]; and (2) there are irregular crustal magnetic fields, predominantly in the southern hemisphere, that set up mini-magnetospheric structures within its ionosphere, and thus solar wind coupling is profoundly different in each hemisphere, a unique occurrence in the solar system.

[33] A significant amount of work has been done by a community of modelers trying to understand this complex ionosphere. In comparison to Earth, the ionosphere on Mars has been remarkably under-sampled, and thus theory and modeling tend to be more advanced than the observational database. The ionosphere-thermosphere problem has been 
Table 1. Summary of Ionospheric Measurements at Mars Prior to the Mars Global Surveyor Mission ${ }^{\mathrm{a}}$

\begin{tabular}{|c|c|c|c|c|c|c|c|}
\hline Mission & Type & Dates & $\# \mathrm{~N}(\mathrm{~h})$ & SZA & Latitude & Longitude & LT \\
\hline \multirow[t]{2}{*}{ Mariner $4^{\mathrm{b}}$} & $\mathrm{FN}$ & 14 June 1965 & 1 & 67 & $50 \mathrm{~S}$ & $177 \mathrm{E}$ & 1300 \\
\hline & FX & 14 June 1965 & $1^{\#}$ & $\sim 115$ & $60 \mathrm{~N}$ & $36 \mathrm{~W}$ & 2340 \\
\hline \multirow[t]{2}{*}{ Mariner $6^{\mathrm{e}}$} & $\mathrm{FN}$ & 31 July 1969 & 1 & 57 & $4 \mathrm{~N}$ & $356 \mathrm{E}$ & 1534 \\
\hline & FX & 31 July 1969 & 1 & 107 & $79 \mathrm{~N}$ & $87 \mathrm{E}$ & 2210 \\
\hline \multirow[t]{2}{*}{ Mariner $7^{\mathrm{e}}$} & FN & 5 Aug 1969 & 1 & 56 & $58 \mathrm{~N}$ & $30 \mathrm{E}$ & 1430 \\
\hline & FX & 5 Aug 1969 & 1 & 130 & $38 \mathrm{~N}$ & $212 \mathrm{E}$ & 0310 \\
\hline Mars $2^{\mathrm{d}, \mathrm{k}}$ & $\mathrm{ON} / \mathrm{X}$ & Nov-Dec 1971 & 4 & $\sim 50$ & $9 \mathrm{~N}-12 \mathrm{~N}$ & $23-360 \mathrm{E}$ & $0900-1600^{+}$ \\
\hline \multirow[t]{2}{*}{ Mariner $9^{f}$} & $\mathrm{ON}$ & 14 Nov-23 Dec 1971 & 76 & $47-56$ & $40 \mathrm{~S}-30 \mathrm{~N}$ & all & $1700-1400$ \\
\hline & $\mathrm{OX}$ & 14 Nov-23 Dec 1971 & 78 & $57-105$ & $34 \mathrm{~N}-65 \mathrm{~N}$ & all & $1700-1400$ \\
\hline \multirow{2}{*}{ Ext. Mission $1^{\mathrm{g}}$} & ON & 7 May-25 June 1972 & 39 & $70-80$ & $40 \mathrm{~S}-86 \mathrm{~N}$ & $60-330 \mathrm{E}$ & $1800-0600$ \\
\hline & OX & 7 May-25 June 1972 & 25 & $95-115$ & $80 \mathrm{~S}-5 \mathrm{~N}$ & all & $0500-1800$ \\
\hline Ext. Mission $2^{\mathrm{g}, \mathrm{h}}$ & $\mathrm{ON} / \mathrm{X}$ & 29 Sept -26 Oct 1972 & 44 & $88-100$ & $65 \mathrm{~S}-55 \mathrm{~S}$ & all & $0900-1300$ \\
\hline \multirow[t]{2}{*}{ Mars $4^{\mathrm{d}, \mathrm{k}, \mathrm{l}, \mathrm{m}}$} & $\mathrm{FN}$ & $10 \mathrm{Feb} 1974$ & 1 & 82 & $52 \mathrm{~S}$ & $17 \mathrm{~W}$ & 0742 \\
\hline & FX & 10 Feb 1974 & 1 & 127 & $9 \mathrm{~S}^{@}$ & $236 \mathrm{~W}$ & 0330 \\
\hline Mars $5^{1}$ & OX & 18 Feb 1974 & 1 & 106 & $38 \mathrm{~N}$ & $214 \mathrm{~W}$ & 0430 \\
\hline Mars $6^{\mathrm{d}, \mathrm{k}, \mathrm{m}}$ & FN & 3 March 1974 & 1 & 72 & $35 \mathrm{~S}$ & $14 \mathrm{~W}$ & $1933^{+}$ \\
\hline \multirow[t]{2}{*}{ Viking $1^{\mathrm{c}}$} & Lander & 20 July 1976 & $1 *$ & $44-37$ & $17 \mathrm{~N}-9 \mathrm{~N}$ & $56-66 \mathrm{~W}$ & 1613 \\
\hline & $\mathrm{ON} / \mathrm{X}^{\mathrm{i}, \mathrm{j}}$ & 20 July $1976-17$ Aug 1980 & $113^{*}$ & $50-125$ & $74 \mathrm{~S}-69 \mathrm{~N}$ & all & $0300-2000$ \\
\hline \multirow[t]{2}{*}{ Viking $2^{\mathrm{c}}$} & Lander & 3 Sept 1976 & 1 & $45-53$ & $42 \mathrm{~N}-34 \mathrm{~N}$ & $236-246 \mathrm{~W}$ & 0949 \\
\hline & $\mathrm{ON} / \mathrm{X}^{\mathrm{i}, \mathrm{j}}$ & 3 Sept $1976-25$ July 1978 & $42^{*}$ & $80-112$ & $67 \mathrm{~S}-73 \mathrm{~N}$ & all & $0400-2100$ \\
\hline
\end{tabular}

${ }^{\mathrm{a}} \mathrm{F}$ : fly-by, O: orbiter; N: ingress, X: egress; ${ }^{\#}$ Poor data; ${ }^{*}$ From 1.88 years $\left(1\right.$ Mars year); ${ }^{+} \pm 2$ hours; ${ }^{\circledR}$ Given as $90 \mathrm{~S}$ in ref ${ }^{1} . \# \mathrm{~N}(\mathrm{~h})$ is the number of electron density profiles, SZA is solar zenith angle.

${ }^{\mathrm{b}}$ Fjeldbo et al. [1966].

${ }^{\mathrm{c}}$ Hanson et al. [1977].

${ }^{\mathrm{d}}$ Kolosov et al. [1975].

${ }^{\mathrm{e}}$ Kliore et al. [1971].

${ }^{\mathrm{f}}$ Kliore et al. [1972].

${ }^{\mathrm{g}}$ Kliore et al. [1973].

${ }^{\mathrm{h}}$ Kliore [1974].

${ }^{\mathrm{i}}$ Kliore [1992].

${ }^{\mathrm{j}}$ Lindal et al. [1979].

${ }^{\mathrm{k}}$ Moroz [1976].

${ }^{1}$ Savich and Samovol [1976].

${ }^{\mathrm{m}}$ Vasilyev et al. [1975].

studied in the framework of detailed photochemistry [e.g., Fox et al., 1995], and with the use of global circulation models (GCMs) by Bougher et al. [1991, 1999, 2000, 2002] and Winchester and Rees [1995]. The first study of coupling between lower and upper atmosphere GCMs has recently been described by Bougher et al. [2001]. The solar wind's interaction with the ionosphere has been studied within the joint contexts of Venus and cometary plasma science [e.g., Shinagawa and Bougher, 1999; Kallio and Janhunen, 2001; Brecht, 1997, 2002], with a new model recently described by Ma et al. [2003], that includes the effect of the crustal magnetic field.

[34] Our results of a literature search for published electron density profiles on Mars are summarized in Table 1 . These discovery mode observations defined the initial phase of ionospheric studies at Mars and provided the foundation material addressed by modelers. Taken as a group, the 433 electron density profiles have a broad coverage in latitude, local time and solar activity; they have enabled basic comparative studies between Mars and Venus [e.g., Zhang et al., 1990a, 1990b; Kliore, 1992], and relationships to solar cycle activity [Hantsch and Bauer, 1990]. In comparison with Earth, however, where incoherent radars obtain complete $\mathrm{N}_{\mathrm{e}}(\mathrm{h})$ profiles within minutes, and ionosondes conduct routine monitoring at 15 min intervals, the total Mars database hardly exceeds a few days of terrestrial data at a single site. Of even greater concern is that the spacing of missions over $\sim 15$ years profoundly limited the continuity in spatial and temporal coverage, and thus comprehensive morphology patterns and their variability characteristics have not been determined with confidence.

[35] The prolonged period of unavailable ionospheric observations after Viking came to a dramatic end in 1997 when the Mars Global Surveyor (MGS) satellite arrived at Mars. With a radio science experiment to measure electron density profiles [Hinson et al., 1999], a plasma instrument to determine solar wind and ionospheric boundaries [Mitchell et al., 2001], an accelerometer to determine neutral atmospheric characteristics [Keating et al., 1998], and a magnetometer that discovered crustal magnetic fields [Acuna et al., 1999], MGS created nothing short of a rebirth of high-altitude environmental science at Mars. In section 4, we describe briefly the use of radio occultation observations to derive electron density altitude profiles and the levels of ionospheric variability they exhibit. In section 5 , we characterize terrestrial ionospheric variability on the same days of the MGS results at Mars and relate both to solar irradiance patterns in section 6 , with summary and conclusions in section 7 .

\section{MGS Radio Science Experiment: Methods and Results}

\subsection{Radio Occultation Techniques}

[36] The MGS radio science (RS) experiment uses an onboard transmitter whose signal is received on Earth as the satellite emerges from its orbit segments behind Mars. The signal is refracted initially by high altitude plasma and then by the dense lower atmosphere. These "angle of arrival" observations are then inverted to yield electron density 


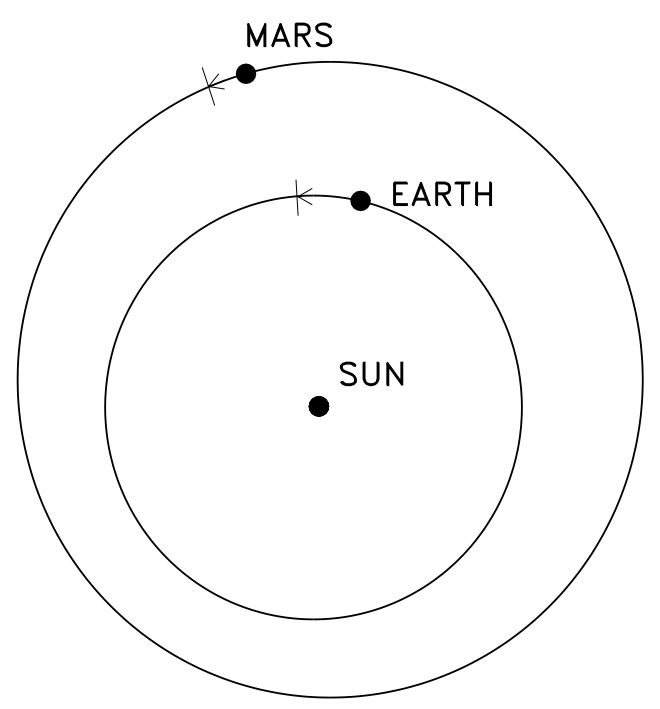

Figure 4. Geometry of Sun, Earth, and Mars during the 19-day period 9-27 March 1999. The solid dots give the position of Earth and Mars on the 9th and the thin solid lines their positions on the 27 th.

profiles and neutral temperature profiles, respectively. The geometrical properties of such limb-probing observations impose limitations upon the local time coverage possible from occultation measurements (e.g., when Mars is at opposition, most of the atmospheric samplings occur at periods near dawn and dusk). These are times when solar illumination effects are changing rapidly at low latitudes, or minimally at high latitudes, and thus not ideal cases for data-model comparisons. For the data-sparse field of planetary ionospheres, these are nevertheless remarkable achievements.

[37] For the MGS ionospheric retrievals, there are no a priori assumptions about the shape of the electron density profile or its peak density, but the electron density is assumed to be zero at altitudes below $90 \mathrm{~km}$. The standard deviation of the measurements varies among the experiments, with a typical value of several thousand per cubic centimeter. Our interest is day-to-day variability, and thus we average two or more MGS profiles to reduce errors in the daily mean profiles to approximately $2-3 \%$. Further details of the MGS/RS experiment are given in the work of Hinson et al. [1999, 2001].

\subsection{Case Studies}

[38] MGS ionospheric profiles have been obtained for several periods since December 1998. The Sun-Earth-Mars geometrical relationship for one of those periods (9-27 March 1999) is shown in Figure 4. This period (with Mars near opposition) is clearly the best case for the study of simultaneous solar effects upon Earth and Mars. For other orbital configurations, e.g., the December 1998 data analyzed by Bougher et al. [2001], when the Sun-EarthMars angle was $\sim 75^{\circ}$ (Mars near quadrature), measurements of solar disk irradiance made at $1 \mathrm{AU}$ would have to be rotated by approximately 7 days, assuming constant solar active regions, to be appropriate for illumination of Mars. The March 1999 period minimizes these concerns and hence is ideal for comparative aeronomic analysis.
[39] Figure 5a shows the 43 individual N(h) profiles obtained during the 19-day period in March 1999. Note that all profiles refer to a narrow range of latitudes $\left(69.7^{\circ}-\right.$ $\left.73.3^{\circ} \mathrm{N}\right)$ and local times $(0336-0406)$. These profiles refer to different longitudes, as well as different days, on Mars and, quite evidently, show considerable variability. Yet, there is a consistent peak with $\mathrm{h}_{\mathrm{m}}$ near $135 \mathrm{~km}$ and a secondary peak near $115 \mathrm{~km}$. The altitude dependence of the standard deviation about the sample mean is given in Figure $5 \mathrm{~b}$ and shows $\mathrm{a} \sim 10 \%$ variability at $\mathrm{h}_{\mathrm{m}}$ and $\sim 15 \%$ for the secondary peak at $115 \mathrm{~km}$; topside variability increases with altitude.

[40] To address variability among individual N(h) profiles, Bougher et al. [2001] analyzed a somewhat smaller dataset composed of the initial $32 \mathrm{~N}(\mathrm{~h})$ profiles obtained over an 8-day period (24-31 December 1998) with latitudes $64.7^{\circ}-67.3^{\circ} \mathrm{N}$ and local times $0318-0418$. The heights of the maximum and secondary peak electron densities showed variations with longitude on Mars, and a correlation analysis was conducted between those heights and the neutral atmosphere density obtained from the accelerometer experiment. The results demonstrated a linkage between wave- 3 patterns in neutral density and the ionospheric heights. As discussed in the context of equation (3), such vertical displacements of the thermosphere would not have a firstorder effect upon the peak electron densities since they occur near constant pressure levels. That is, the ionospheric $\mathrm{h}_{\mathrm{m}}$ values could vary in absolute height units, but their electron densities $\left(\mathrm{N}_{\mathrm{m}}\right)$ would remain constant since the amount of penetrating ionizing radiation depends only on the amount of overlying atmosphere.

[41] Our interest in this study concerns day-to-day variability, and thus in Figure 5c we cast the 43 profiles into daily average values. Most of the 19 days had two to three profiles taken over a $\sim 50$ degree longitude range, and these were averaged to form the daily mean profiles. One day (10 March) had no MGS profiles and a second day (21 March) had only a single profile. Excluding the latter led to 17 average daily $\mathrm{N}(\mathrm{h})$ profiles at a mean local time of 0352. In Figure 5d, the standard deviations about the 17-day mean are shown. Note that some of the variability from Figure $5 b$ has been reduced by the daily/longitude averaging. The remaining variability ( $\sim 5-7 \%$ at the main peak and $\sim 10 \%$ at the secondary peak) thus represent our characterization of ionospheric day-to-day variability on Mars for this period.

\section{Terrestrial Ionospheric Variability During 9-27 March 1999}

[42] The MGS measurements described in Figure 5 pertain to the rather special conditions of summer solstice at high latitudes, i.e., it is $\sim 04$ LT at $\sim 71.5^{\circ} \mathrm{N}$ and the Sun is $\sim 13$ degrees above the horizon $\left(\chi \sim 77^{\circ}\right)$. On Earth, these days span an equinox period and thus "midnight sun" conditions do not occur anywhere on the planet. In Antarctica, Zhongshan $\left(69^{\circ} \mathrm{S}, 76^{\circ} \mathrm{E}\right)$ provides the closest equivalent site for ionosonde measurements and, quite fortunately, data were taken on all 17 days for which MGS observations are available at Mars. At 0400 LT, the Sun is below the horizon at Zhongshan, but at 0830 LT, the solar zenith angle is $\sim 77^{\circ}$ (with a diurnal minimum at noon of $68^{\circ}$ ), conditions favorable for comparison with the MGS results. 


\section{9-27 March 1999: 43 Individual Profiles}
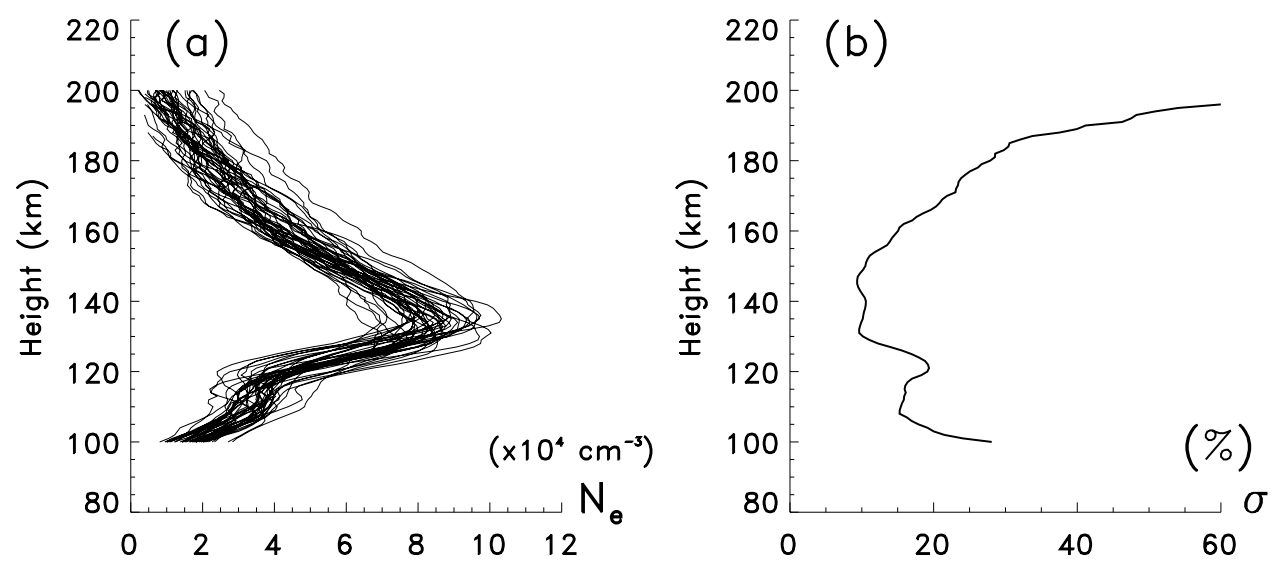

\section{9-27 March 1999:}

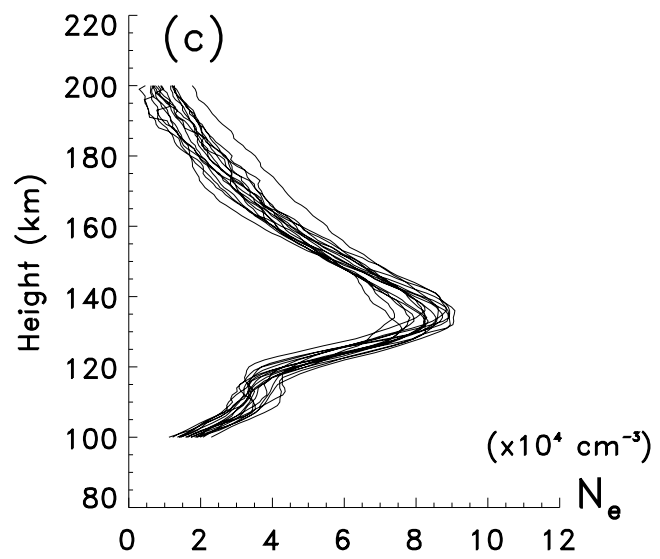

17 Daily Mean Profiles

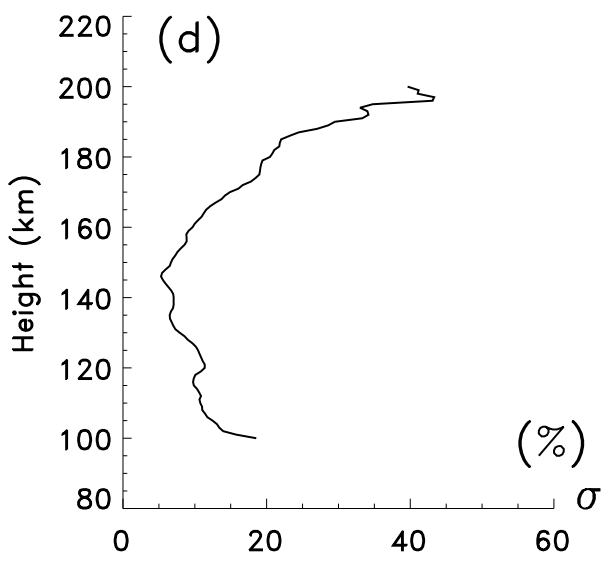

Figure 5. Electron density profiles from the Mars Global Surveyor (MGS) radio science experiment for 9-27 March 1999. All measurements refer to latitudes in the range $69.7^{\circ}-73.3^{\circ} \mathrm{N}$ and $26.5^{\circ}-73.0^{\circ} \mathrm{W}$ on Mars. The local times sampled were 3.6-4.1 hours, and the solar zenith angles were $76.5^{\circ}-77.8^{\circ}$. (a) The 43 individual profiles obtained ( 1 to 3 per day distributed in longitude) and (b) the standard deviation about the sample mean. (c) Longitude-averaged profiles for each day containing two or more profiles from Figure 5a, and (d) the daily variability about that sample's mean.

[43] The diurnal patterns of the ionospheric layers above Zhongshan are shown in Figure 6. Obviously, there is considerable variability at this site. The lower panel showing the daily $\mathrm{N}_{\mathrm{m}} \mathrm{E}$ curves (formed from $\mathrm{f}_{\mathrm{o}} \mathrm{E}$ hourly values with $0.1 \mathrm{MHz}$ resolution, as done in Figures 2 and 3) shows a basic solar control of diurnal behavior. Yet, the standard deviations $(\Sigma)$ for the daytime period are rather large ( $\sim 20 \%)$, and they increase as evening occurs ( $\sim 40-65 \%$ from 1800-2000 LT). The reason for this unusually high E-layer variability is the proximity of Zhongshan to the auroral zone in the southern hemisphere. Thus the "auroral-E" electron density enhancements produced by precipitating magnetospheric particles dominate the day-to-day variability patterns at most local times. This is most unfortunate from the perspective of comparative aeronomy but a nice reminder that ionospheric physics on Earth is a rich field of solar-terrestrial coupling.

[44] In Figures 2 and 3, we showed the variability of the terrestrial E-, F1- and F2-layers above Bermuda and Eglin (Florida), two "pure midlatitude" sites. Since their E- and F2-layer variabilities were consistent with many previous studies, we will return to those sites for our initial assessment of ionospheric variability due to photochemical processes on Earth during 9-27 March 1999. Their 17-day means and associated variabilities during the MGS sample period matched those of the full monthly datasets shown in Figures 2 and 3. To maximize diagnostic accuracy for the photochemical E-layer, we will also abandon the requirement of matching the low elevation angle of the MGS data, and simply examine the day-to-day variabilities for mid-day hours (1100-1300 LT). Using the mean of three hourly values also reduces the observational errors in forming a daily value from ionosonde samplings with $0.1 \mathrm{MHz}$ resolution to the same levels associated with the MGS daily profiles $(2-3 \%)$.

\section{Comparative Photochemical Ionospheres on Earth and Mars}

\subsection{Solar Variability in March 1999}

[45] Having defined the terrestrial and martian datasets appropriate for comparative study, we now turn to a 


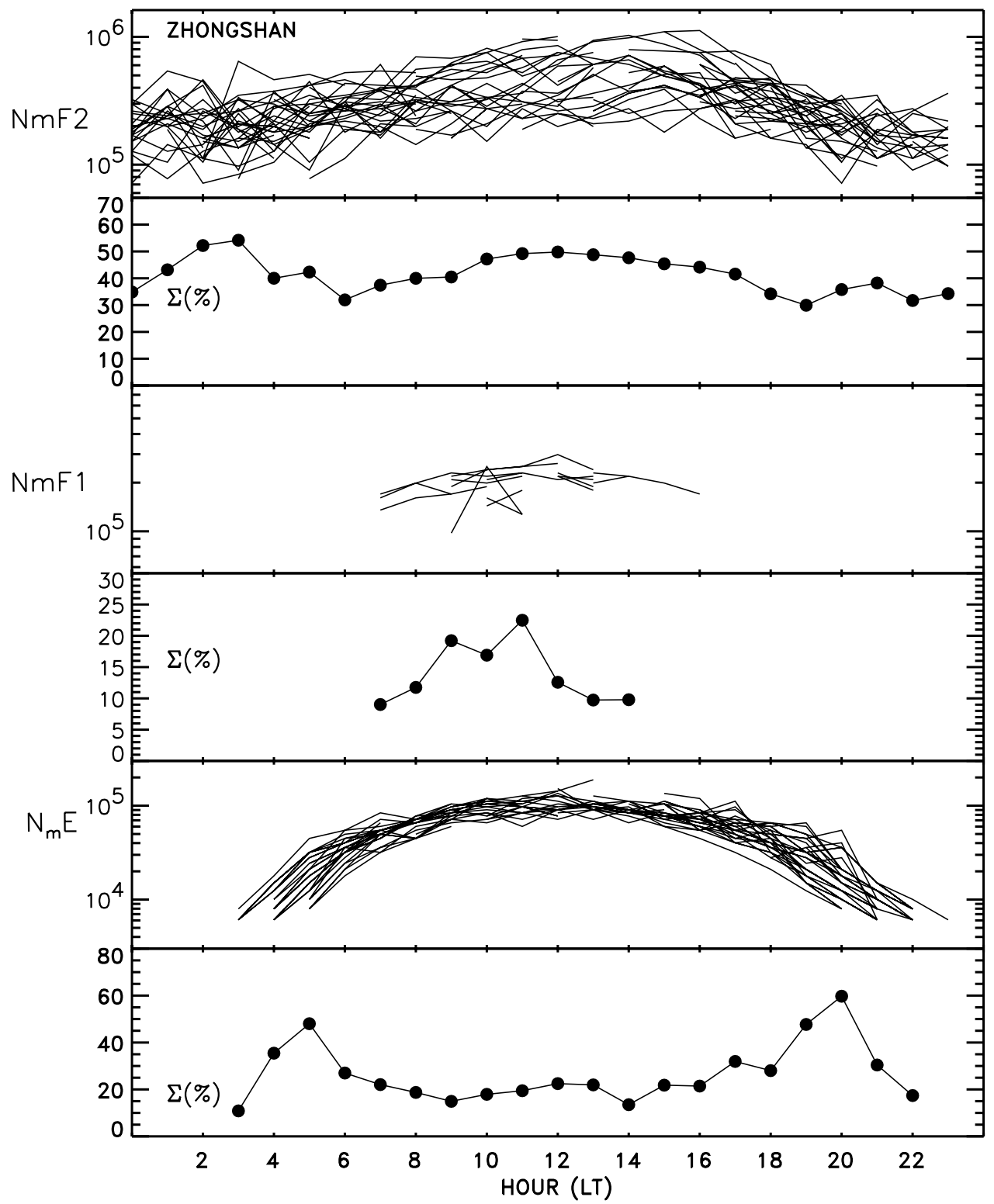

Figure 6. Ionosonde data from the PRC's Zhongshan station in Antarctica $\left(69^{\circ} \mathrm{S}, 76^{\circ} \mathrm{E}\right)$ for March 1999, using the same format as in Figures 2 and 3. Note that the variabilities $(\Sigma)$ at this auroral zone station are larger than those at the midlatitude stations in Figures 2 and 3.

description of the Sun's variability during the period of interest. The solar energy flux versus wavelength (called solar irradiance) that reached both planets each day between 9 and 27 March 1999 had to be virtually identical. Figure 7 shows several indices used to characterize solar activity observed at 1 AU during that period. Quite fortunately, the emissions from the Sun were not constant and thus Earth and Mars experienced the passage of a solar active region well suited for comparative aeronomic studies during a rather short period. The historical index to gauge solar activity (the $10.7 \mathrm{~cm}$ solar radio flux, F10.7) varied from 103 units to 154 units, a range comparable to the solar cycle's mean levels for a year of mid-to-low activity and a year of moderate solar maximum, respectively.
[46] The neutral atmospheres above terrestrial sites and at the MGS measurement point on Mars had to respond in some way to such changes in solar input. The first-order effect of interest here, however, is the photoionization of molecules spanning these days of solar variability, and thus we will assume that any temporary changes in the neutral atmospheres are of secondary importance to the values of peak electron density. To characterize the solar input for use in equation (5), we will use the E10.7 curve in Figure 7. This index is used increasingly in aeronomy to characterize the actual portion of the solar spectrum (EUV + X-rays) that accounts for ionization of atmospheric constituents [see Tobiska et al., 2000, 2003]. Thus we will use E10.7 as a proxy for the solar photon flux S at $1 \mathrm{AU}$ in equation (5), and examine how it and the other parameters 


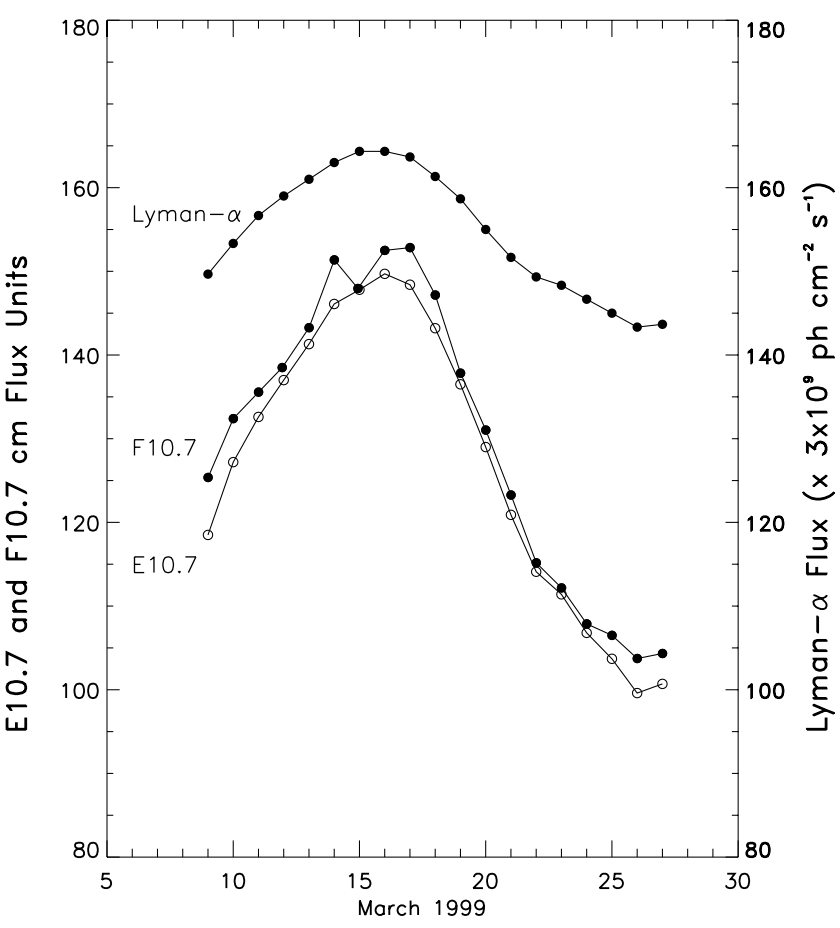

Figure 7. Three indices that portray solar activity during the period of MGS data at Mars: Lyman- $\alpha$ emission, F10.7 radio flux and the new E10.7 index that combines several diagnostics of solar activity for use in aeronomic studies [Tobiska, 2000].

of this equation compare at Earth and Mars. There are several types of comparisons that can be made.

\subsection{Comparison of Day-to-Day Photochemical Equilibrium on Earth and Mars}

[47] As shown in equation (5), simple photochemical equilibrium within an invariant atmosphere at a fixed distance from the Sun would result in a quadratic relationship between the maximum electron density and the solar radiation responsible for ionization, i.e., $\mathrm{N}_{\mathrm{m}}^{2} \sim \mathrm{S}$. To test this relationship, we use the 17 daily values of $\mathrm{N}_{\mathrm{m}}$ on Mars, $\mathrm{N}_{\mathrm{m}}$ E at Bermuda and at Eglin, averaged over 1100-1300 LT, and the corresponding 17 values of the E10.7 indices to arrive at the results in Figure 8. The best fit lines to the data are given by

$$
\begin{gathered}
\left(\mathrm{N}_{\mathrm{m}}(\text { Mars })\right)^{2}=0.033(\text { E10.7 })+2.81\left(10^{9} \mathrm{e}^{-} / \mathrm{cm}^{6}\right) \\
\left(\mathrm{N}_{\mathrm{m}}(\text { Earth })\right)^{2}=0.100(\text { E10.7 })+14.18\left(10^{9} \mathrm{e}^{-} / \mathrm{cm}^{6}\right) .
\end{gathered}
$$

In creating Figure 8, attention was given to the timing of the various measurements. For E10.7, its component that depends on solar radio flux (F10.7) comes from observations made each day at 1700-2300 UT (for a mean of 2000 UT). At Bermuda and Eglin, noon conditions are at 1600 and 1800 UT, respectively, for a two-station mean of $1700 \mathrm{UT}$. At Mars, the MGS observations each day spanned 1800-2300 UT, and the "daily mean profiles" shown in Figure 5 had an average time of 2054 UT. Thus in all cases, the solar flux is determined prior to or close to the time of the ionospheric observations on Mars and Earth. Figure 8 offers convincing evidence for solar control of the photochemical ionospheric layers on Mars and Earth. If all photochemical species and parameters were truly the same on both planets, the slopes of the lines in Figure 8 would differ only by the square of their respective distances from the Sun. For Earth at $1 \mathrm{AU}$ and Mars at $1.52 \mathrm{AU}$, this amounts to a factor of 2.25. The empirical values shown in Figure 8 have a ratio of about 3 , implying that the assumptions leading to the use of equation (5) for scaling studies are generally appropriate one. Finally, we note that while solar irradiance changes account for the overall trend in Figure 8, there is still residual variability. It appears uncorrelated at the two planets, and thus would likely be a combination of observational uncertainties and variabilities causes by other processes unique to each planet.

\section{COMPARATIVE IONOSPHERES: 9-27 MARCH 1999}
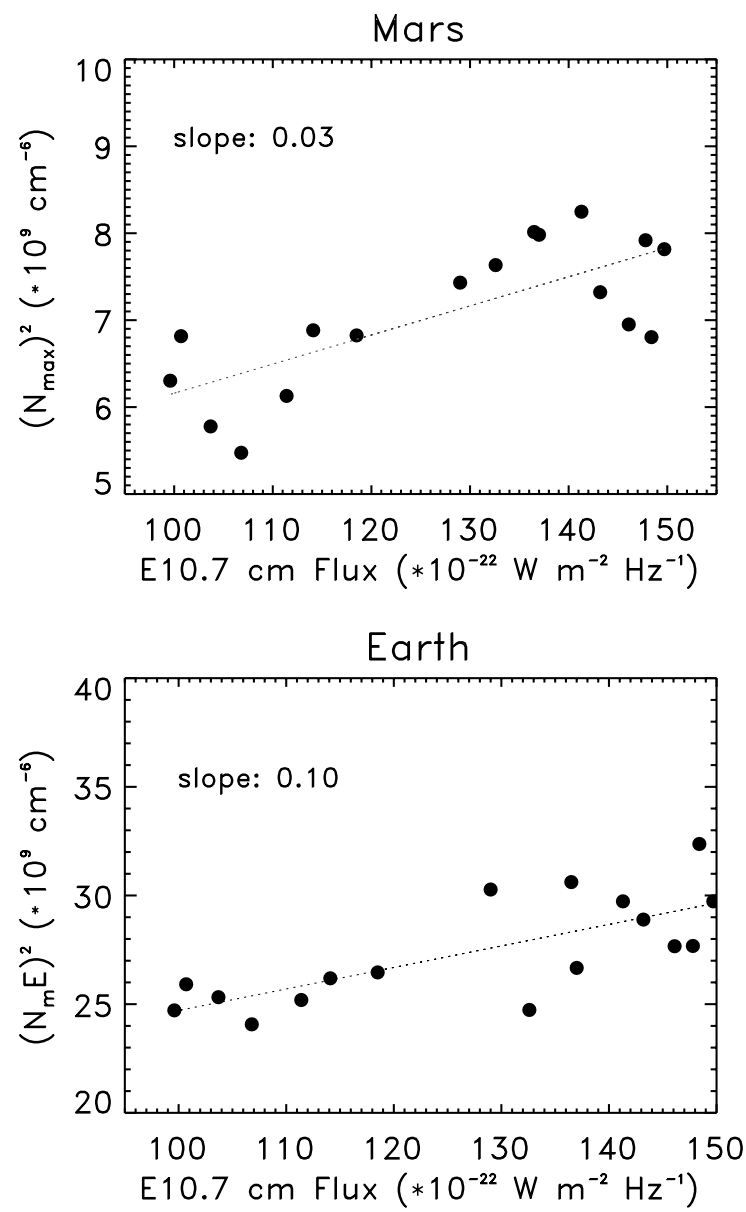

Figure 8. Comparisons of $\mathrm{N}_{\mathrm{m}}$ on Mars and same-day values of $\mathrm{N}_{\mathrm{m}} \mathrm{E}$ on Earth with the corresponding E10.7 daily indices for 17 days within the period 9-27 March 1999. Daytime hourly values (1100-1300 LT) were averaged from the Bermuda and Eglin ionosonde sites to form the terrestrial daily values with experimental uncertainties approximately equal to those for the MGS daily means $(2-3 \%)$. For correlations within the framework of photochemical equilibrium, the square of the electron density is related to solar flux by a linear fit (see text). 
[48] While there are no independent dataset on Mars to confirm the MGS results for this month, there are multiple sites on Earth available to confirm the terrestrial trend in Figure 8. While the global ionosonde network is large, Bermuda and Eglin were selected because they alone had complete coverage for 9-27 March 1999. Finding sites that were at comparable "pure midlatitudes" but at vastly different longitudes, and with more than 10 days of E-region data reported, proved rather difficult. Useable data were available from Ahmedabad (India) and Hobart (Tasmania). Adding those sites to the Bermuda, Florida and Antarctic sites already described, we show in Figure 9 correlation results for the E-layers at all five terrestrial locations examined in this study. The patterns from Ahmedabad and Hobart, while not as complete as the results from the Bermuda/Florida longitude sector, point to a reasonable confirmation of those trends in the Asian sector and in the southern hemisphere. For Zhongshan, the auroral influence upon E-layer variability clearly dominates. Most encouraging for the non-auroral sites is that the slopes relating their $\mathrm{N}_{\mathrm{m}}^{2}$ to E10.7 are all consistent at $\sim 0.1$.

\subsection{Comparing Absolute Values of Electron Density at Earth and Mars}

[49] Equation (5) can be recast to separate $\mathrm{N}_{\mathrm{m}}$ and the purely geometrical factors from the photochemical parameters, yielding,

$$
\mathrm{N}_{\mathrm{m}}^{2} \mathrm{D}^{2} \sec \chi=\mathrm{S} \eta / \alpha \mathrm{eH} \sim \text { constant }
$$

The left side of equation (9) involves known quantities, and thus one can readily test to see if their product leads to a "constant" for the right-hand term. This is done by taking the values of $\mathrm{N}_{\mathrm{m}}^{2}$ (in units of $10^{9} \mathrm{~cm}^{-6}$ ) at E10.7 = 125 units for Earth and Mars from Figure 8, and noting that for equinox conditions $\chi \sim$ latitude (which is $31^{\circ}$ for the mean of Bermuda and Eglin), while for Mars $\chi=77^{\circ}$; $D=1$ for Earth and 1.5 for Mars. The computed value of $\mathrm{N}_{\mathrm{m}}^{2} \mathrm{D}^{2} \mathrm{sec}$ $\chi$ at Mars (69) is about twice the terrestrial value (32). At our present level of investigation, agreement of squared quantities to within a factor of 2 seems quite satisfactory. It implies that all the $\mathrm{N}_{\mathrm{m}}$ values at Mars are $\sim 40 \%$ larger than anticipated from the simplifying set of assumptions that led to equation (9). Considering the array of physical parameters on the right-hand side that also form the constant, a factor of two difference in their product is reasonable. Differences will occur in the spectral range for S and the ionization efficiencies $\eta$ leading to the production of $\mathrm{O}_{2}^{+}$at each planet, as will the appropriate scale height $\mathrm{H}$ to use at each planet. As shown in the work of Bougher et al. [2002], $\mathrm{H}$ can vary in the $5-10 \mathrm{~km}$ range at both planets for the altitudes of interest here. Our computations show that the main uncertainty in $\mathrm{H}$ is due to rapidly changing temperatures with altitude, a far more important trend on Earth than on Mars. In Chapman theory, this enters as a modification to the exponent of the $\sec \times$ term in equation (9). Titheridge [2000] shows this factor to be 1.2-1.3 under most conditions at Earth; using MSIS for March 1999 we find it somewhat larger (1.4). This correction would be appropriate only for the terrestrial constant, and it only reduces the factor of 2 differences by about $10 \%$. A larger effect would result from the ionization frequencies for $\mathrm{CO}_{2}$ and $\mathrm{O}_{2}$, defined as $\mathrm{J}$,

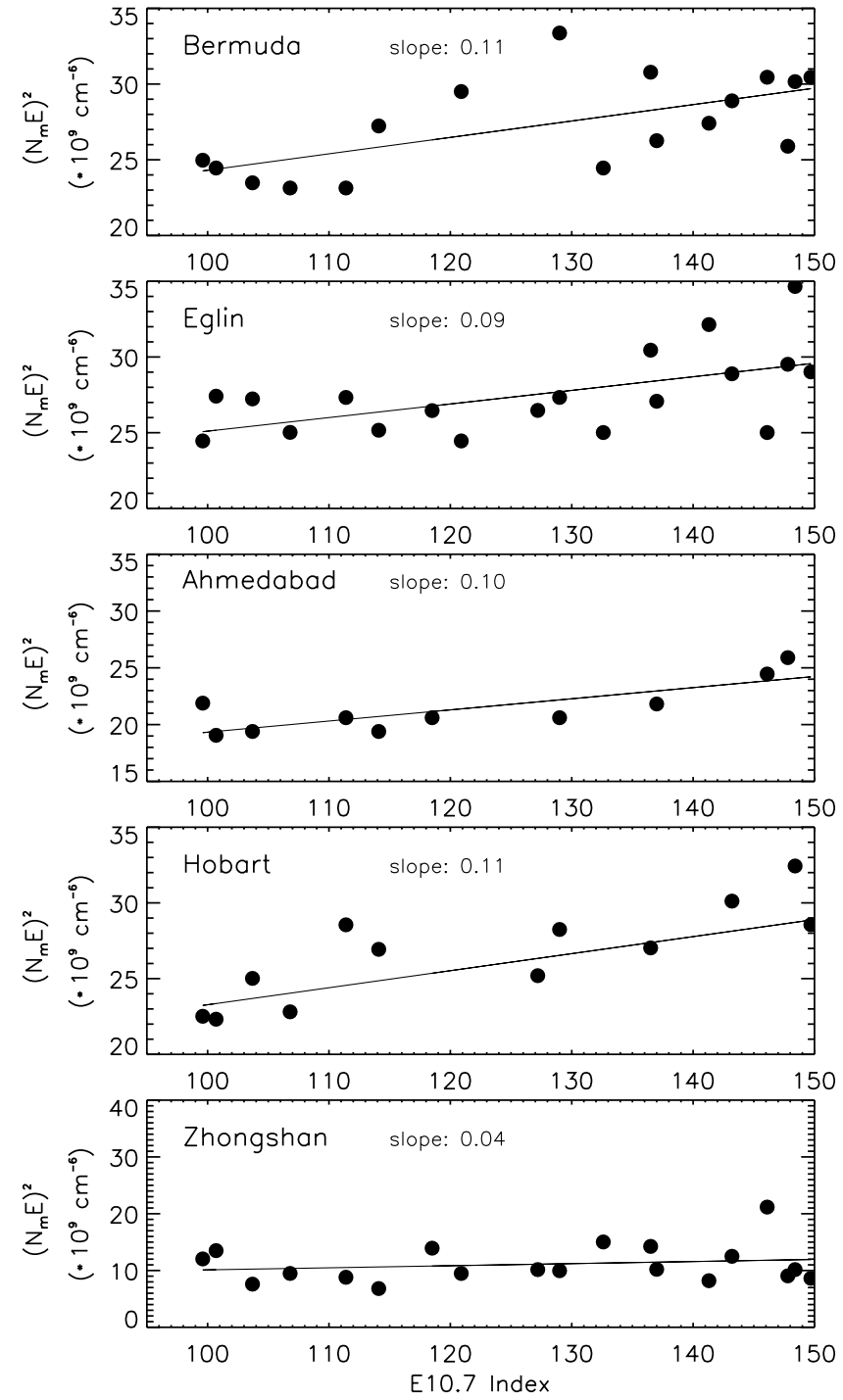

Figure 9. Comparisons of terrestrial $\mathrm{N}_{\mathrm{m}} \mathrm{E}$ patterns versus solar flux using the same format as in Figure 8 for the 17 day MGS period in March 1999. In addition to the Bermuda and Elgin sites used to create Figure 8, the ionosonde station at Ahmedabad (India, $23^{\circ} \mathrm{N}, 72^{\circ} \mathrm{E}$ ), was selected because of its very different longitude, and the station in Hobart (Tasmania, Australia, $43^{\circ} \mathrm{S}, 147^{\circ} \mathrm{E}$ ), provides mid-latitude coverage from the southern hemisphere. Bermuda and Elgin each have full coverage for the 17 days of MGS data during 9-27 March 1999, Ahmedabad had 10 days and Hobart 12 days. The lowest panels give results from the Antarctic auroral zone station Zhongshan, using data from Figure 6.

the ionization rate per unit neutral gas molecule at the top of the atmosphere, i.e., $\langle\mathrm{S} \sigma\rangle$ averaged over wavelength. As shown in Table 9.2 in the work of Schunk and Nagy [2002], the J-value for $\mathrm{CO}_{2}$ is larger than for $\mathrm{O}_{2}$ at $1 \mathrm{AU}$, making the $\mathrm{S}$ $\eta$ proxy in equation (4) the dominant source of difference between Earth and Mars.

\subsection{Comparing Earth and Mars Ionospheres at Constant Solar Zenith Angle}

[50] Returning to equation (5), there is one final scaling test to be made, namely the $\mathrm{N}_{\mathrm{m}} \sim 1 / \mathrm{D}$ relation for identical 
latitude and solar zenith angle conditions at the two planets. The only terrestrial site where this is possible is Zhongshan, where average conditions in the E-layer should reflect solar production (but not its variability, as discussed above). The Zhongshan monthly mean at $77^{\circ}$ (at 0830 LT in Figure 6) is $7 \times 10^{4} \mathrm{e}^{-} / \mathrm{cm}^{3}$ which, when scaled down by $\mathrm{D}=1.52$, gives $4.6 \times 10^{4} \mathrm{e}^{-} / \mathrm{cm}^{3}$ for the Martian ionosphere. The observed mean value from MGS in Figure 5 is $8 \times 10^{4} \mathrm{e}^{-/}$ $\mathrm{cm}^{3}$ which would have to be reduced by $40 \%$, in agreement with the estimate made in section 6.3 using equation (9).

\section{Conclusions}

[51] This first attempt to relate ionospheric variability on two planets results from the recent availability of consecutive day observations of the electron density profiles from the Mars Global Surveyor (MGS) satellite during a period when Mars and Earth were nearly aligned with the Sun. The MGS daily peak electron densities were analyzed in conjunction with daily values of the terrestrial E-layer's peak density and a daily solar index for production. A unified photochemical equilibrium explanation for the trends seen on both planets has been obtained. The period sampled did not include episodes of enhanced geomagnetic activity, and the MGS profiles did not show evidence for a compressed ionopause location, and thus solar wind induced perturbations (that might have an influence via downward coupling to photochemical layers) could not be addressed and remain as an open, interesting issue. While solar flux changes alone were sufficient to account for the basic trends in observed variabilities, residuals do remain. These are uncorrelated and appear to be larger at Mars. Different types of upward coupling from neutral atmosphere dynamics are perhaps the major unknown sources of quiet-time variability at both planets. Detailed modeling of this period using a constant neutral atmosphere and 17 daily irradiance spectra has been conducted by Martinis et al. [2003], and values of $\pm 5-10 \%$ variability are easily accounted for by solar effects alone. Finally, the MGS dataset is extensive and future observational periods to be analyzed may well contain evidence for solar wind impact effects upon the ionospheric profiles. This would expand current notions of "space weather" ionospheric variability on Earth to a more general case of solar/terrestrial-planet space weather.

[52] Acknowledgments. Ionosonde data used in this study were provided by the World Data Center in Boulder, Colorado. Support for this work at Boston University was provided by the NASA MGS Data Analysis grants program and by seed research funds from the Center for Space Physics. We are grateful to Luke Moore for assistance in the data analysis and Carlos Martinis for useful discussions. Funding for work at Stanford University was provided by the Mars Global Surveyor Project.

[53] Arthur Richmond thanks Jane L. Fox and another reviewer for their assistance in evaluating this paper.

\section{References}

Acuna, M. H., et al., The history of Mars: Global distribution of crustal magnetism discovered by the Mars Global Surveyor MAG/ER experiment, Science, 284, 790-793, 1999.

Appleton, E., Global morphology of the E- and F1-layers of the ionosphere, J. Atmos. Terr. Phys., 15, 9-12, 1959.

Banks, P. M., and G. Kockarts, Aeronomy, part A, Academic, San Diego, Calif., 1973.

Bauer, S., Physics of Planetary Ionospheres, Springer-Verlag, New York, 1973.
Bougher, S. W., S. Engel, R. G. Roble, and B. Foster, Comparative terrestrial planet thermospheres: 2. Solar cycle variation of global structure and winds at equinox, J. Geophys. Res, 104, 16,591-16,611, 1999.

Bougher, S. W., S. Engel, R. G. Roble, and B. Foster, Comparative terrestrial planet thermospheres: 3 . Solar cycle variation of global structure and winds at solstices, J. Geophys. Res, 105, 17,669-17,692, 2000.

Bougher, S., S. Engel, D. Hinson, and J. Forbes, Mars Global Surveyor radio science electron density profiles: Neutral atmosphere implications, Geophys. Res. Lett., 28, 3091-3094, 2001.

Bougher, S. W., R. G. Roble, and T. Fuller-Rowell, Simulations of the upper atmospheres of the terrestrial planets, in Atmospheres in the Solar System: Comparative Aeronomy, Geophys. Monogr. Ser., vol. 130, edited by M. Mendillo, A. Nagy, and J. H. Waite, AGU, Washington, D. C., 2002.

Brecht, S. H., Hybrid simulations of the magnetic topology of Mars, J. Geophys. Res., 102, 4743-4750, 1997.

Brecht, S. H., Numerical techniques associated with simulations of the solar wind interaction with non-magnetized bodies, in Atmospheres in the Solar System: Comparative Aeronomy, Geophys. Monogr. Ser., vol. 130, edited by M. Mendillo, A. Nagy, and J. H. Waite, AGU, Washington, D. C., 2002.

Chapman, S., The absorption and dissociative or ionizing effect of monochromatic radiation in an atmosphere on a rotating earth, Proc. Phys. Soc. London, 43, 26-45, 1931.

Davies, K., Ionospheric Radio Waves, 460 pp., Blaisdell, Waltham, Mass., 1969.

Fjeldbo, G., et al., Models for the atmosphere of Mars based on the Mariner 4 occultation experiment, J. Geophys. Res., 71, 2307-2316, 1966.

Forbes, J. M., Wave coupling, in Atmospheres in the Solar System: Comparative Aeronomy, Geophys. Monogr. Ser., vol. 130, edited by M. Mendillo, A. Nagy, and J. H. Waite, AGU, Washington, D. C., 2002.

Forbes, J. M., and M. Hagan, Diurnal Kelvin wave in the atmosphere of Mars: Towards an understanding of "stationary" density structures observed by the MGS accelerometer, Geophys. Res. Lett., 27, 3563$3566,2000$.

Forbes, J. M., S. E. Palo, and X. Zhang, Variability of the Ionosphere, J. Atmos. Sol. Terr. Phys., 62, 685-693, 2000.

Fox, J. L., P. Zhou, and S. W. Bougher, The Martian thermosphere/ionosphere at high and low solar activities, Adv. Space Res., 17(11), 203-218, 1995.

Fuller-Rowell, T. J., M. V. Codrescu, and P. Wilkinson, Quantitative modeling of the ionospheric response to geomagnetic activity, Ann. Geophys., $18,766-781,2000$

Hanson, W. B., et al., The Martian ionosphere as observed by the Viking retarding potential analyzers, J. Geophys. Res., 82, 4351-4363, 1977.

Hantsch, M. H., and S. J. Bauer, Solar control of the Mars ionosphere, Planet. Space Sci., 38, 539-542, 1990.

Hargreaves, J. K., The Solar-Terrestrial Environment: An Introduction to Geospace, Cambridge Univ. Press, New York, 1992.

Hinson, D. P., R. A. Simpson, J. D. Twicken, and G. L. Tyler, Initial results from radio occultation measurement with Mars Global Surveyor, J. Geophys. Res., 104, 26,997-27,012, 1999

Hinson, D. P., G. L. Tyler, J. L. Hollingsworth, and R. J. Wilson, Radio occultation, measurements of forced atmospheric waves on Mars, J. Geophys. Res., 106, 1468-1480, 2001

Kallio, E., and P. Janhunen, Atmospheric effects of proton precipitation in the Martian atmosphere and its connection to the Mars-solar wind interaction, J. Geophys. Res., 106, 5617-5634, 2001.

Keating, G. M., et al., The structure of the upper atmosphere of Mars: In-situ accelerometer measurements from Mars Global Surveyor, Science, 279, 1672-1676, 1998 .

Kelley, M., The Earth's Ionosphere: Plasma Physics and Electrodynamics, Int. Geophys. Ser., vol. 43, 484 pp., Academic, San Diego, Calif., 1989

Kliore, A. J., Exploration of the planetary system, in Proceedings of the Symposium, Torun, Poland, Sept. 5-8, 1973, pp. 295-316, D. Reidel, Norwell, Mass., 1974.

Kliore, A. J., Radio occultation observations of the ionospheres of Mars and Venus, in Venus and Mars: Atmospheres, Ionospheres and Solar Wind Interactions, Geophys. Monogr. Ser., vol. 66, edited by J. Luhmann, M. Tatrallyay, and R. Pepin, pp. 265-276, AGU, Washington, D. C., 1992.

Kliore, A. J., G. Fjeldbo, and B. L. Seidel, Summary of Mariner 6 and 7 radio occultation results on the atmosphere of Mars, Space Res., XI, 165$175,1971$.

Kliore, A. J., et al., The atmosphere of Mars from Mariner 9 radio occultation measurements, Icarus, 17, 484-516, 1972.

Kliore, A. J., et al., S band radio occultation measurements of the atmosphere and topography of Mars with Mariner 9: Extended mission coverage of polar and intermediate latitudes, J. Geophys. Res., 78, 4331-4351, 1973. 
Kolosov, M. A., et al., Results of investigations of the atmosphere of Mars by the method of radio transillumination by means of the automatic interplanetary stations Mars-2, Mars-4, and Mars-6, Cosmic Res., 13, $54-59,1975$.

Kouris, S. S., and L. M. Muggleton, Diurnal variation in the E-layer ionization, J. Atmos. Sol. Terr. Phys., 35, 133-139, 1973a.

Kouris, S. S., and L. M. Muggleton, World morphology of the Appleton E-layer seasonal anomaly, J. Atmos. Sol. Terr. Phys., 35, 141-151, 1973 b.

Lindal, G. F., et al., Viking radio occultation measurements of the atmosphere and topography of Mars: Data acquired during 1 Martian year of tracking, J. Geophys. Res., 84, 8443-8456, 1979.

Ma, Y., A. F. Nagy, K. C. Hansen, D. L. DeZeeuw, T. I. Gombosi, and K. G. Powell, Three-dimensional multispecies MHD studies of the solar wind interaction with Mars in the presence of crustal fields, J. Geophys. Res., 107(A10), 1282, doi:10.1029/2002JA009293, 2003.

Martinis, C., J. Wilson, and M. Mendillo, Modeling day-to-day ionospheric variability on Mars, J. Geophys. Res., 108(A10), 1383, doi:10.1029/ 2003JA009973, 2003

Mitchell, D. L., et al., Probing Mars crustal magnetic field and ionosphere with the MGS electron reflectometer, J. Geophys. Res., 106, 23,41923,428, 2001

Moroz, V. I., The atmosphere of Mars, Space Sci. Rev., 19, 763-843, 1976.

Nagy, A., and T. Cravens, Solar system ionospheres, in Atmospheres in the Solar System: Comparative Aeronomy, Geophys. Monogr. Ser., vol. 130, edited by M. Mendillo, A. Nagy, and J. H. Waite, AGU, Washington, D. C., 2002.

Nicolet, M., Effects of the atmospheric scale-height gradient on the variation of ionization and short-wave absorption, J. Atmos. Terr. Phys., 1, $141-146,1951$.

Ratcliffe, J. A., (ed.), Physics of the Upper Atmosphere, Academic, San Diego, Calif., 1960.

Rishbeth, H., The centenary of solar-terrestrial physics, J. Atmos. Sol. Terr. Phys., 63, 1883-1890, 2001.

Rishbeth, H., and O. K. Garriott, Introduction to Ionospheric Physics, Academic, San Diego, Calif., 1969

Rishbeth, H., and M. Mendillo, Patterns of F2-layer variability, J. Atmos Sol. Terr. Phys., 63, 1661-1680, 2001.

Savich, N. A., and V. A. Samovol, The night time ionosphere of Mars from Mars-4 and Mars-5 dual-frequency radio occultation measurements, Space Res., 1009-1011, 1976.
Schunk, R. W., STEP Handbook of Ionospheric Models, edited by R. W. Schunk, pp. 153-171, Utah State Univ., Logan, Utah, 1996.

Schunk, R., Ionospheric models for Earth, in Atmospheres in the Solar System: Comparative Aeronomy, Geophys. Monogr. Ser., vol. 130, edited by M. Mendillo, A. Nagy, and J. Waite, AGU, Washington, D. C., 2002. Schunk, R. W., and A. Nagy, Ionospheres: Physics, Plasma Physics and Chemistry, 584 pp., Cambridge Univ. Press, New York, 2002.

Shinagawa, H., and S. W. Bougher, A two-dimensional MHD model of the solar wind interaction with Mars, Earth Planets Space, 51, 55-60, 1999.

Titheridge, J. E., Modelling the peak of the ionospheric E-layer, J. Atmos. Sol. Terr. Phys., 62, 93-114, 2000.

Titheridge, J. E., Model results for the daytime ionospheric E and valley regions, J. Atmos. Sol. Terr. Phys., 65, 129-137, 2003.

Tobiska, W. K., SOLAR2000 irradiances for climate change, aeronomy, and space systems engineering, Adv. Space Res., in press, 2003.

Tobiska, W. K., T. Woods, F. Eparvier, R. Viereck, L. Flyod, D. Bouwer, G. Rottman, and O. R. White, The SOLAR2000 empirical solar irradiance model and forecast tool, J. Atmos. Sol. Terr. Phys., 62, 1233-1250, 2000

Vasilyev, M. B., et al., Preliminary results of the two-frequency radio-transillumination of the martian ionosphere by means of the "Mars" automatic interplanetary stations in 1974, Cosmic Res., 13, 41-45, 1975.

Winchester, C., and D. Rees, Numerical models of the Martian coupled thermosphere and ionosphere, Adv. Space Res., 15(4), 51-68, 1995.

Zhang, M. H. G., J. G. Luhmann, A. J. Kliore, and J. Kim, A postPioneer Venus reassessment of the Martian dayside ionosphere as observed by radio occultation methods, J. Geophys. Res., 95, $14,829-14,839,1990$ a.

Zhang, M. H. G., J. G. Luhmann, and A. J. Kliore, An observational study of the nightside ionosphere of Mars and Venus with radio occultation methods, J. Geophys. Res., 95, 17,095-17,102, 1990 b.

D. Hinson, Department of Electrical Engineering, Stanford University, Stanford, CA 94305-9515, USA. (hinson@rocc.stanford.edu)

M. Mendillo, H. Rishbeth, S. Smith, and J. Wroten, Center for Space Physics, Boston University, Boston, MA 02215, USA. (mendillo@bu.edu; hr@phys.soton.ac.uk; smsm@bu.edu; jwroten@bu.edu) 